\title{
PELATIHAN PEMBUATAN DAN PENGOPERASIAN INSTALASI BIOGAS SISTEM KONTINU PADA KELOMPOK TANI KARYA BERSAMA, RT 15 KANDANG LIMUN KOTA BENGKULU
}

\section{TRAINING OF MAKING AND OPERATING OF CONTINUOUS BIOGAS INSTALLATION AT FARMER GROUP KARYA BERSAMA KANDANG LIMUN BENGKULU}

\author{
Oleh: \\ Eka Angasa $^{* 1}$, Ghufiral, Marisadonna Asteria ${ }^{2}$ \\ ${ }^{1}$ Jurusan Kimia FMIPA, ${ }^{2}$ Pendidikan Kedokteran FKIK Universitas Bengkulu \\ eka.angasa@gmail.com
}

\begin{abstract}
ABSTRAK
Kegiatan pengabdian dilaksanakan dikarenakan sering terjadi kelangkaan gas sehingga harga gas menjadi tinggi. Kelangkaan dan tingginya harga gas menyebabkan masyarakat kembali beralih ke kayu untuk keperluan memasak sehari-hari. Sementara Kelonpok Tani Karya Bersama mempunyai potensi yang besar berupa limbah kotoran sapi yang dapat digunakan sebagai penghasil biogás. Biogas dapat dimanfaatkan untuk memasak seharihari. Pemanfaatan kotoran sapi menjadi biogás belum dilakukan karena tidak ada sumber daya manusia yang mampu mengolah kotoran sapi tersebut. Untuk itu, dilakukan pelatihan embuatan dan pengoperasian instalasi biogás sistem kontinu pada Kelompok Tani Karya Bersama, RT 15 Kandang Limun, Kota Bengkulu. Pelatihan dilaksanakan pada Kelompok Tani ini sebagai contoh bagi masyarakat lainnya. Kelompok tani ini telah berhasil membuat dan mengoperasikan instalasi biogas, sehingga ke depan diharapkan menjadi fasilitator munculnya instalasi-instalasi baru dan masyarakat peternak sapi tidak bergantung lagi pada gas dan minyak tanah.
\end{abstract}

Keywords: Biogas, Instalasi biogás, digester

\section{PENDAHULUAN}

Keputusan Pertamina menaikkan harga LPG $12 \mathrm{~kg}$ sebesar Rp 6.300-8.000 per tabung sejak 1 April 2015, mengakibatkan kelangkaan LPG 3 Kg di beberapa daerah Kota Bengkulu. Kelangkaan LPG $3 \mathrm{~kg}$ terutama terjadi pada daerah pinggiran Kota Bengkulu seperti Kelurahan Pematang Gubernur dan Kandang Limun, Kecamatan Muara Bangkahulu. Kelangkaan ini dipicu oleh banyaknya konsumen beralih ke LPG $3 \mathrm{Kg}$ yang biasanya menggunakan LPG $12 \mathrm{Kg}$ yang kini harganya mencapai Rp. 170.000/tabung. Konsumen yang beralih ke LPG $3 \mathrm{Kg}$ tidak hanya masyarakat menengah ke bawah tetapi juga pelaku industri rumah tangga seperti rumah makan, catering, dan industri rumah lainnya. Hal ini diamini oleh seorang pengecer gas, Arsin, warga RT 21 Pematang Gubernur, yang mengatakan bahwa sejak kenaikan LPG $12 \mathrm{~kg}$, permintaan LPG $3 \mathrm{~kg}$ meningkat lebih dari $100 \%$ sedangkan permintaan LPG $12 \mathrm{~kg}$ menurun drastis bahkan 
tidak laku sama sekali. Lebih lanjut Arsin mengatakan kelangkaan ini juga disebabkan pengurangan jatah pembelian 25-40\% dari jatah sebelumnya. Kelangkaan LPG $3 \mathrm{Kg}$ dan tingginya permintaan, menyebabkan harga LPG $3 \mathrm{Kg}$ merangkak naik. Berdasarkan informasi dari warga dan penjual/pengecer gas di Kelurahan Kandang Limun dan Pematang Gubernur, harga LPG $3 \mathrm{Kg}$ naik menjadi Rp. 18.000,-/tabung dari sebelumnya Rp. 16.000. Bahkan pada waktu tertentu, harga bisa mencapai Rp. 20.000,-/tabung.

Kelangkaan dan kenaikan harga LPG $3 \mathrm{~kg}$ begitu terasa dampaknya bagi warga petani/peternak yang ada di Kelurahan Pematang Gubernur dan Kandang Limun yang keberadaannya sudah mulai tersingkir dengan kehadiran beberapa perumahan yang banyak muncul belakangan ini. Bahkan beberapa dari mereka, tidak lagi menggunakan LPG $3 \mathrm{Kg}$ dan beralih menggunakan kayu untuk keperluan memasak sehari-hari (Gambar 1). Kondisi inilah yang mendorong tim untuk mencarikan solusi yang tepat bagi petani/peternak lainnya dengan memanfaatkan potensi yang ada.
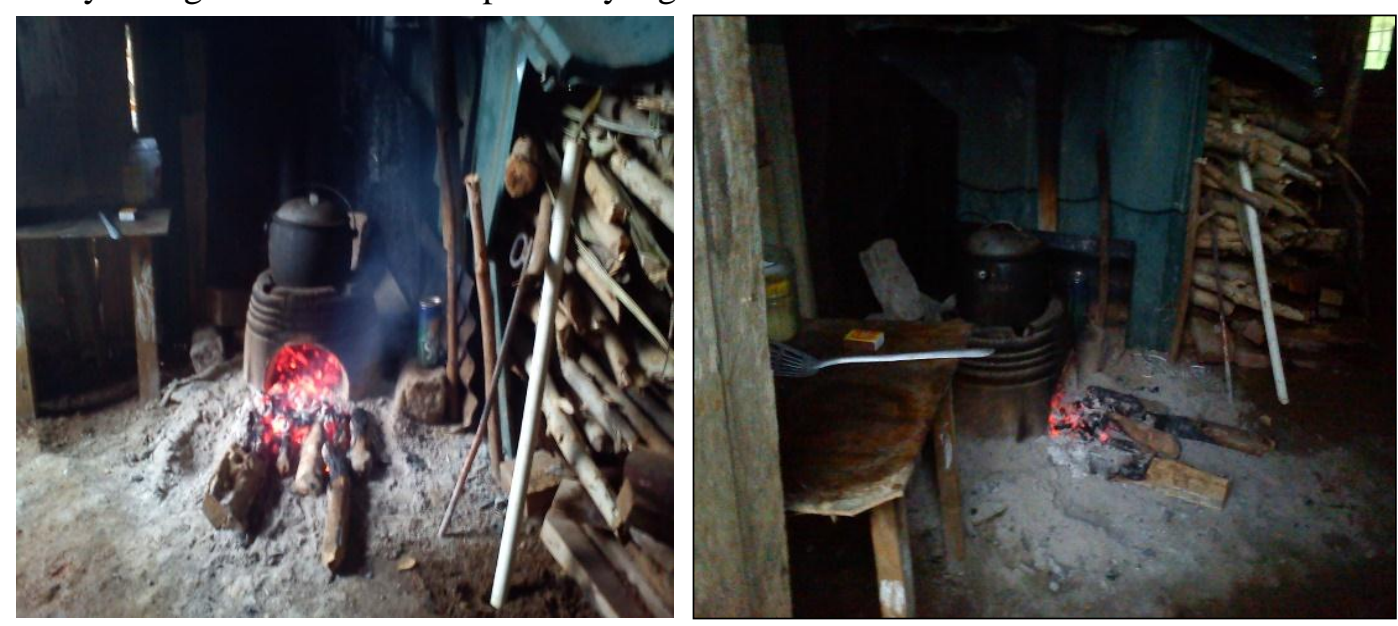

Gambar 1. Kondisi dapur salah satu mitra

Salah satu potensi yang dapat digunakan untuk mengganti kayu sebagai bahan bakar adalah memanfaatkan kotoran ternak menjadi biogas yang ketersediaannya cukup tinggi. Petani/peternak di RT 15 Kandang Limun sebagian mempunyai sapi antara 3-15 ekor yang jika diolah kotorannya mampu memenuhi kebutuhan gas petani/peternak itu sendiri. Menurut Junus (1987), rata-rata seekor sapi menghasilkan kotoran sebanyak $29 \mathrm{~kg} / \mathrm{hari}$. Setiap satu kg kotoran sapi dapat menghasilkan 0,023-0,040 $\mathrm{m}^{3}$ biogas. Dengan demikian 3 ekor sapi menghasilkan kotoran sebanyak $87 \mathrm{~kg} / \mathrm{hari}$. Jika diolah menjadi biogás maka dihasilkan 2,001-3,48 $\mathrm{m}^{3} /$ hari. Biogas ini mampu memenuhi kebutuhan gas untuk memasak sehari-hari. Namun sampai saat ini, kotoran yang dihasilkan belum dimanfaatkan. Kotoran terbuang begitu saja sebagai limbah yang justru menyebarkan penyakit bagi masyarakat sekitar (Gambar 2). Salah satu faktor penyebab tidak termanfaatkannya potensi dari kotoran sapi adalah tidak adanya Sumber Daya Manusia (SDM) yang mampu mengolah kotoran sapi menjadi biogas. 


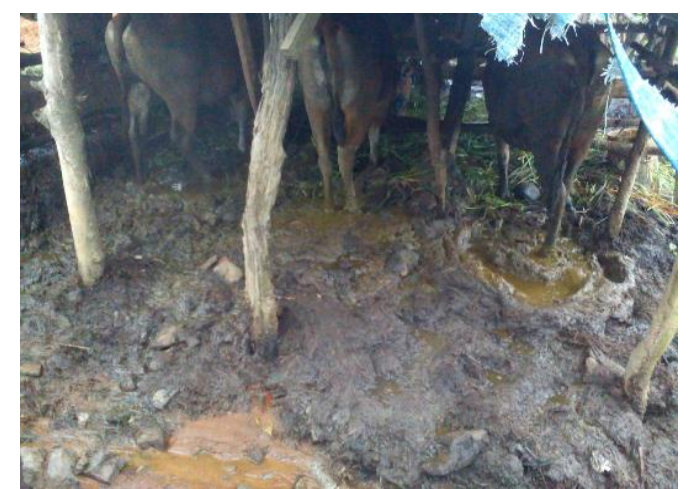

(a)

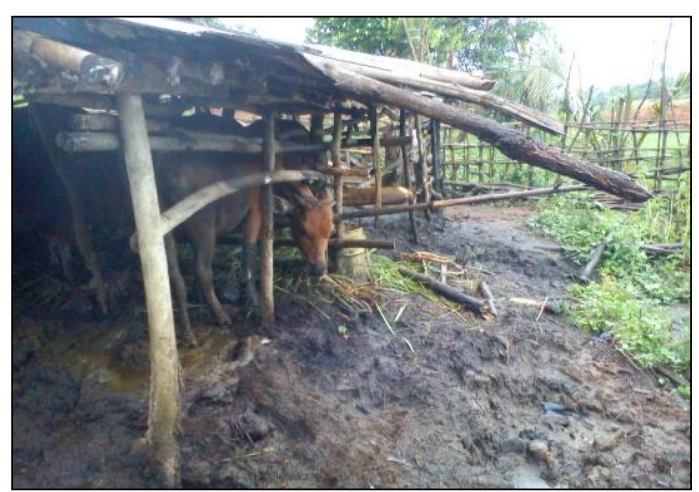

(b)

Gambar 2. Kondisi kandang sapi salah satu mitra

a) Kandang Sapi Keluarga Giman, b) Kotoran sapi sumber limbah

Melihat kondisi keluarga petani/peternak yang sudah banyak beralih menggunakan kayu bakar dikarenakan kelangkaan dan kenaikan LPG 3 kg sebagai akibat kenaikan LPG $12 \mathrm{~kg}$, sedangkan ada potensi berupa kotoran sapi yang dapat diolah menjadi biogas dengan ketersediaannya cukup tinggi, maka sangat penting untuk melakukan pelatihan dan pembuatan instalasi biogas yang bersifat kontinu. Sehingga hasilnya dapat digunakan untuk memasak sehari-hari bagi peternak sapi yang ada di Kelurahan Kandang Limun. Berdasarkan informasi dari pihak kelurahan dan Ketua RT serta survey langsung tim di lapangan yang ditetapkan sebagai mitra untuk kegiatan pengabdian ini adalah Kelompok Tani Karya Bersama yang ada di RT 15 Kelurahan Kandang Limun.

\section{METODE PENGABDIAN}

\section{Alat dan Bahan}

Alat dan bahan yang dipakai pada kegiatan pengabdian ini meliputi: tangki air berbahan PVC kapasitas $2000 \mathrm{~L}$, plastik polietilen dengan ketebalan $0.2 \mathrm{~mm}$, kompor gas satu tungku, pipa $1 \frac{1}{2}$ inci, pipa 3 inci, sambungan L, T, dan I, lem silikon, slang ukuran $1 / 2$ inci, lem paralon, lakban, solder, dan tali karet.

\section{Cara Kerja}

Kegiatan pengabdian dilaksanakan dengan tahapan sebagai berikut:

\section{Rancang Bangun Instalasi Biogas}

Instalasi biogas yang dirancang pada kegiatan bersifat kontinu, seperti yang ditunjukkan oleh Gambar 3 (Ginting, 2006). 


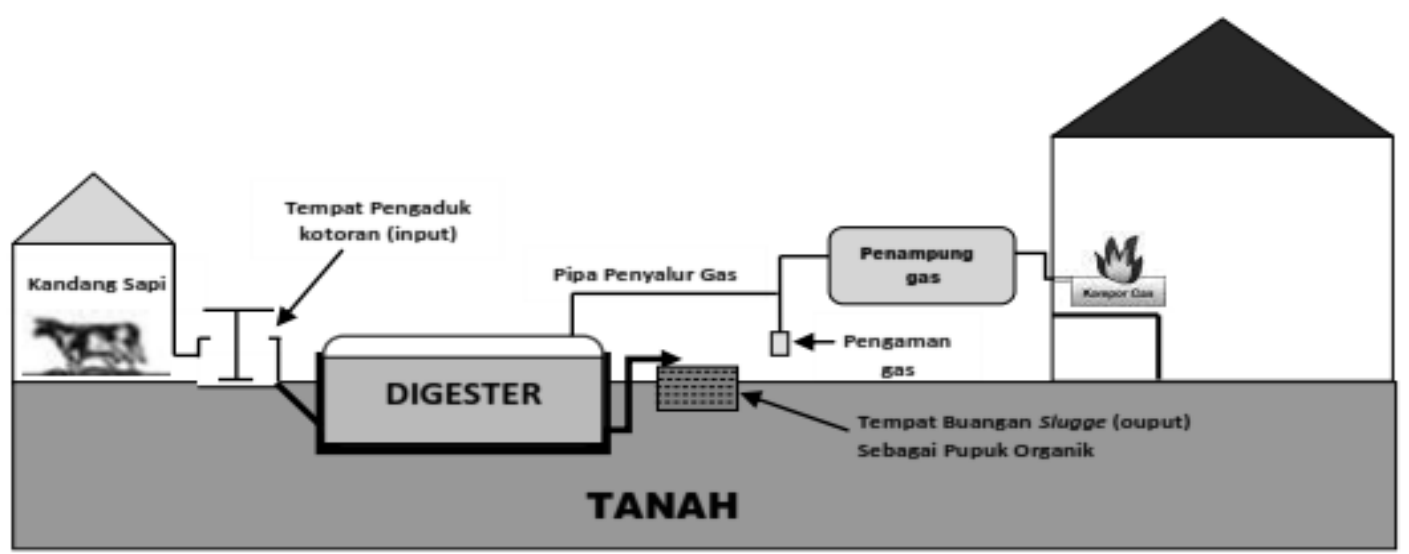

Gambar 3. Skema instalasi biogas yang dibuat

Tahapan dalam pembuatan instalasi biogas adalah (Andi, 2008):

a. Pembuatan digester

Digester dibuat dengan menggunakan tangki air yang berbahan PVC dengan kapasitas 2000 L. Digester dirancang sesuai dengan Gambar 1. Pipa feed masuk dan feed keluar digunakan pipa 3 inci. Pada feed masuk terdiri dari dua lobang. Lobang satu digunakan untuk feed masuk, sedangkan lobang kedua tempat keluar angin ketika feed dimasukkan. Pada feed keluar dirancang bentuk S. Bagian atas digester dipasang pipa 1/2 inci sebagai tempat keluarnya gas.

b. Pembuatan penampung gas

Penampung gas yag digunakan adalah plastik berbahan polietilen dengan ketebalan $0.2 \mathrm{~mm}$. Salah satu ujung plastik dipasang pipa $1 / 2$ inci, diikat, dan dilakban. Ujung yang lain dipasang pipa $1 / 2$ inci dengan cara yang sama dan dihubungkan dengan kompor gas.

c. Penggabungan semua komponen instalasi

Setelah komponen digester dan penampung gas selesai dibuat, dilakukan penggabungan semua komponen instalasi di lokasi. Digester diletakkan pada tempat yang dekat dengan sumber feed. Digester ditanam dalam tanah. Digester dihubungkan dengan penampung gas menggunakan pipa $1 / 2$ inci. Antara digester dengan penampung gas dipasang pipa $\mathrm{T}$ yang diimasukkan ke dalam tabung yang berisi air. Penampung gas dengan kompor gas dihubungkan dengan pipa $1 / 2$ inci dan slang ukuran $1 / 2$ inci. Di dekat kompor gas dipasang stop kran yang berfungsi sebagai pengatur gas.

\section{Pengoperasian instalasi biogas}

Kotoran sapi (feed) dicampur dengan air dengan perbandingan 1:1. Campuran ini dimasukkan ke dalam digester sampai penuh yang ditunjukkan dengan adanya feed yang keluar pada pipa keluar. Sebelum dimasukkan feed, ke dalam campuran ditambahkan lumpur 1 ember $( \pm 15$ L). Karena lantai sudah dicor, maka lantai hanya perlu disiram tiap 
pagi sehingga airnya langsung masuk ke digester. Campuran dibiarkan sampai gas terbentuk, yang ditandai dengan adanya penggelembungan pada penampung gas. Gas pertama yang terbentuk dibuang terlebih dahulu. Setelah gas mulai terbentuk, dilakukan penambahan feed setiap pagi kira-kira sebanyak 20 liter. Agar tekanan gas meningkat, maka ditempatkan beban pada penampung gas.

\section{HASIL DAN PEMBAHASAN}

\section{Rancang Bangun Instalasi Biogas Sistem Kontinu}

Pembuatan digester diawali dengan memasang pipa sebagai feed masuk dengan menggunakan soldier, agar lobang pada tangki sesuai dengan pipa, sehingga memudahkan dalam pengeleman. Pada feed masuk dipasang 2 buah pipa. Pipa yang satu berfungsi sebagai tempat untuk memasukkan feed. Pipa yang kedua berfungsi sebagai tempat keluar udara ketika feed dimasukkan. Setelah pipa feed masuk terpasang, dilanjutkan dengan pemasangan pipa feed keluar. Pipa feed keluar dirancang berbentuk S. Tujuannya agar mudah menampung feed yang keluar. Tinggi pipa feed keluar harus disesuaikan dengan tinggi feed dalam digester sehingga tidak menyumbat gas keluar. Setelah itu dipasang pipa untuk menyalurkan gas yang terbentuk ke penampung gas. Pada tahap akhir pembuatan digester dilakukan pengecekan kebocoran dengan menggunakan air. Jika terdapat kebocoran, dilakukan pengeleman ulang. Gambar digester ditunjukkan oleh Gambar 4a.

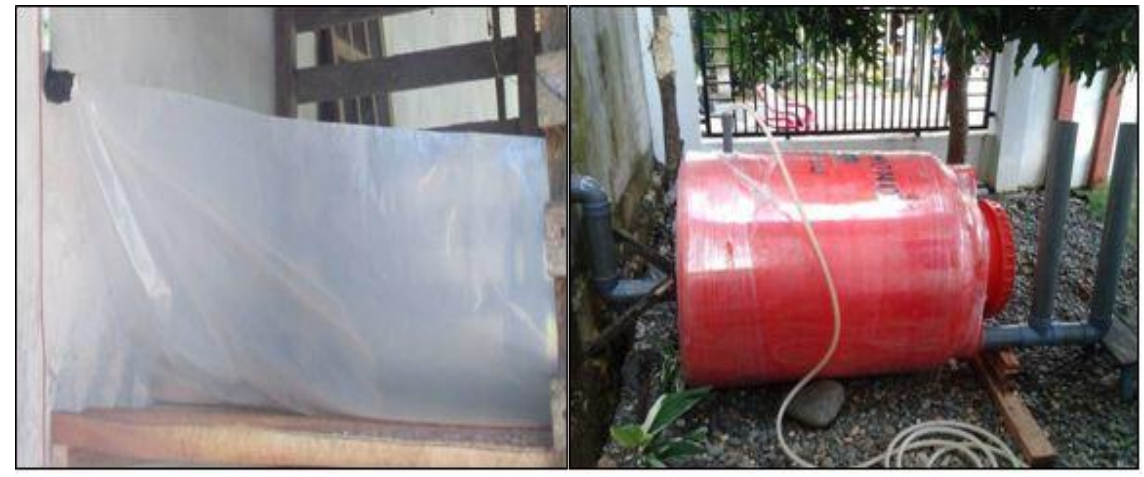

(a)

(b)

Gambar 4. Bentuk instalasi biogas a) digester, b) Penampung gas

Pembuatan instalasi dilanjutkan dengan pembuatan penampung gas. Penampung gas yang digunakan terbuat dari plastik berukuran $0.2 \mathrm{~mm}$ (Gambar 4b). Salah satu keuntungan penggunaan plastik sebagai penampung gas adalah plastik dapat menahan beban sehingga tekanan gas ke kompor jadi besar. Setelah palstik terpasang, dilanjutkan dengan pemasangan kompor gas. Kompor gas yang digunakan adalah kompor gas komersil satu tungku (Gambar 5a). Sebelum digunakan untuk biogas, spuyer kompor gas harus dibuka, dikarenakan tekanan biogas rendah sehingga tidak mampu memompa gas ke bunner. Untuk pengamanan dipasang regulator yang terbuat dari pipa yang dicelupkan ke air (Gambar 5b). Regulator ini juga berfungsi sebagai water trap. 


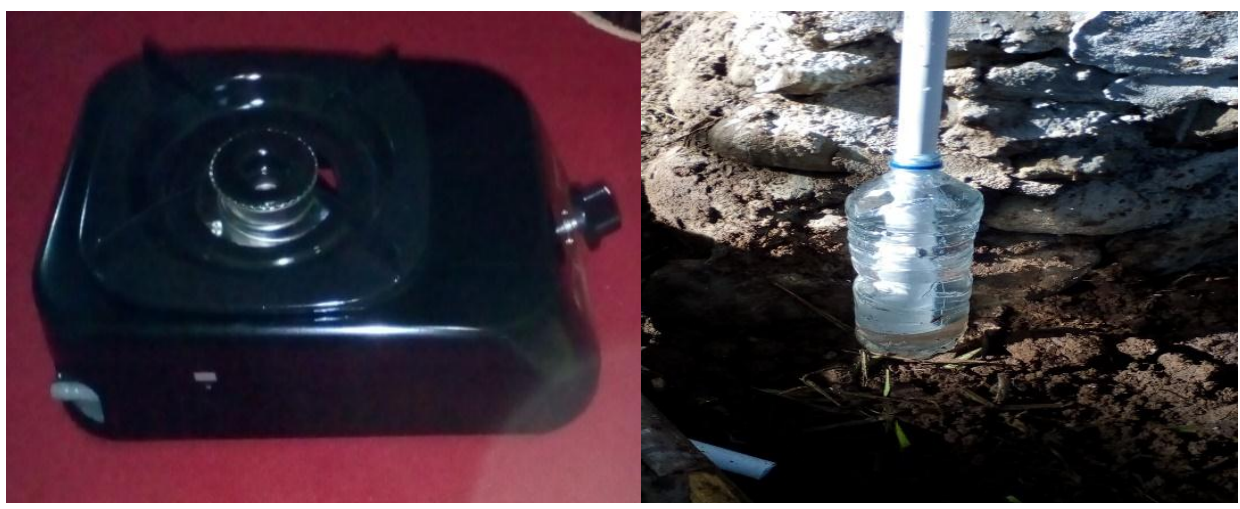

(a)

(b)

Gambar 5. a) Kompor gas yang digunakan, b) bentuk regulator

\section{Pelatihan Pembuatan dan Pengoperasian Instalasi Biogas pada Mitra}

Instalasi yang sudah siap, dipasang di lokasi pengabdian. Tahapan pelaksanaan di lokasi adalah:

1. Kegiatan dimulai dengan ceramah dan diskusi tentang pemanfaatan kotoran sapi sebagai penghasil gas.

2. Pelatihan pembuatan dan pengoperasian instalasi biogas.

Pertama dijelaskan kepada mitra bahwa kotoran sapi dapat diolah menjadi biogas. Biogas dapat digunakan untuk keperluan memasak. Setelah itu dijelaskan komponen instalasi biogas yang akan digunakan mitra. Lalu dilanjutkan dengan pemasangan instalasi dengan melibatkan mitra. Pemasangan instalasi dimulai dengan pemasangan digester. Digester ditempatkan di lokasi yang dekat dengan sumber feed. Tujuannya adalah memudahkan waktu pengisian digester. Digester ditanam dalam tanah dengan tujuan menghindari kebocoran dan lebih aman (Gambar 6).

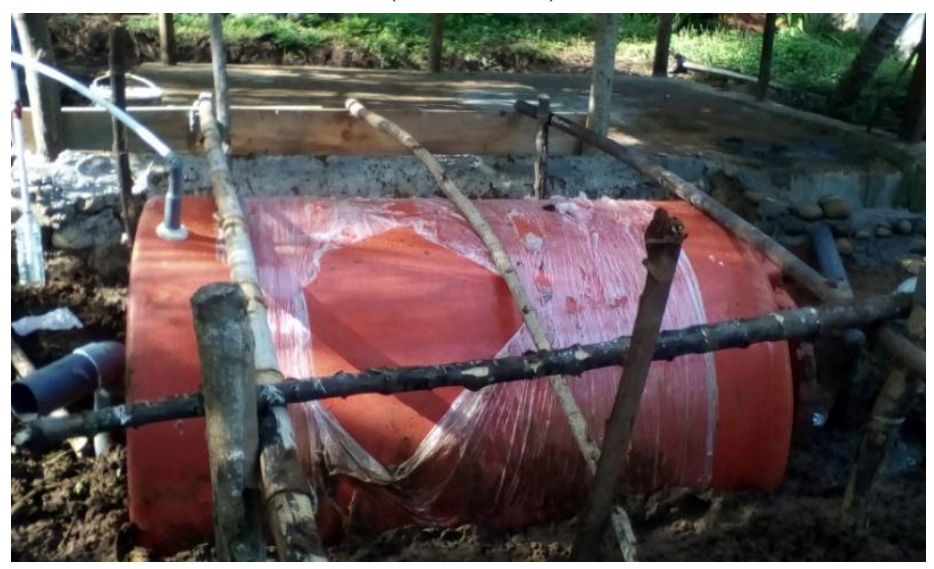

Gambar 6. Digester yang ditanam dalam tanah

Setelah digester terpasang, dilanjutkan dengan pemasangan penampung gas dan kompor gas. Penampung gas ditempatkan di daerah yang aman dari kebocoran, sedangkan kompor gas ditempatkan di dapur (Gambar 7a). Digester, penampung gas, dan kompor gas dihubungkan dengan pipa 1/2 inci. Stop kran untuk instalasi dipasang sebanyak 2 buah. Stop 
kran yang satu dipasang sebelum penampung gas dan stop kran yang kedua dipasang sebelum kompor. Untuk pengamanan dipasang regulator yang terbuat dari pipa yang dicelupkan ke air (Gambar 7b). Regulator ini juga berfungsi sebagai water trap.

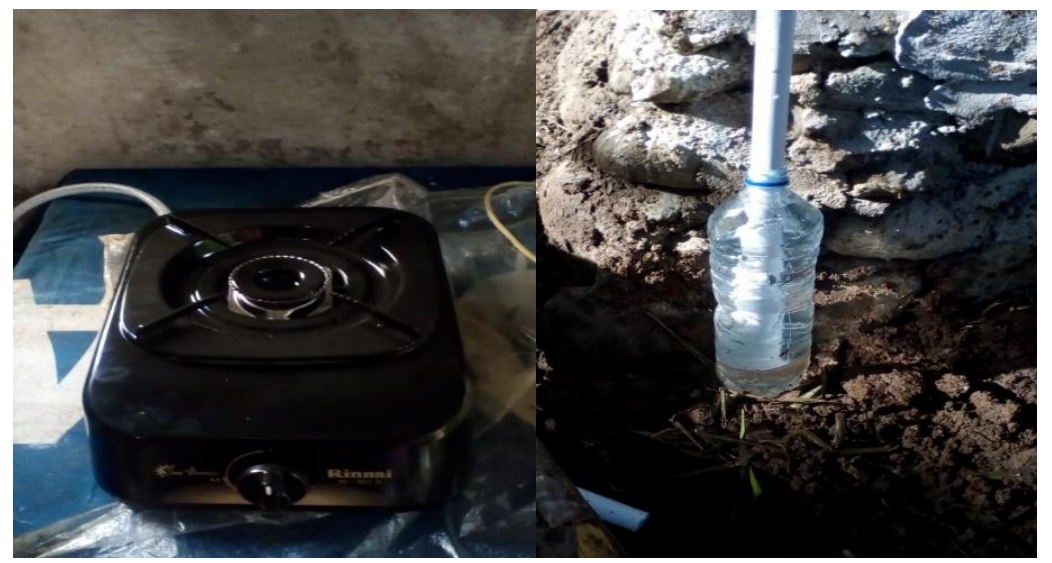

Gambar 7. a) Kompor gas yang sudah terpasang di dapur, b) regulator

Setelah instalasi terpasang, kegiatan dilanjutkan dengan pelatihan pengoperasian instalasi dan langsung dipraktekkan. Digester diisi dengan feed yang dicampur air dengan perbandingan 1:1. Kotoran harus bebas dari bahan-bahan kimia seperti tali plastik karena dapat mengganggu kerja bakteri sehingga gas yang dihasilkan tidak maksimal atau tidak ada sama sekali. Kotoran sapi yang digunakan adalah kotoran yang fresh. Sebelum dimasukkan feed, ke dalam digester ditambahkan lumpur sebagai sumber bakteri. Selain itu, penambahan lumpur akan mempercepat terbentuknya gas. Setelah lumpur dimasukkan, dilanjutkan dengan penambahan feed.

\section{Hasil Penerapan Instalasi Biogas}

Pada hari ke-10, gas sudah terbentuk yang ditandai dengan menggelembungnya penampung gas (Gambar 8a). Hasil ini lebih cepat dari waktu normal yang biasanya dibutuhkan, gas terbentuk antara 3-4 minggu. Pada hari ke 15, gas sudah dapat digunakan dengan lama pemakaian \pm 1 jam. Gas yang dihasilkan berwarna biru sama halnya dengan menggunakan gas elpiji (Gambar 8b). Gas ini telah dimanfaatkan oleh petani untuk memasak seperti memasak air, menggoreng, dan menumis sayuran (Gambar 8c). Setelah gas terbentuk, dilakukan penambahan feed setiap pagi $\pm 20 \mathrm{~L}$.

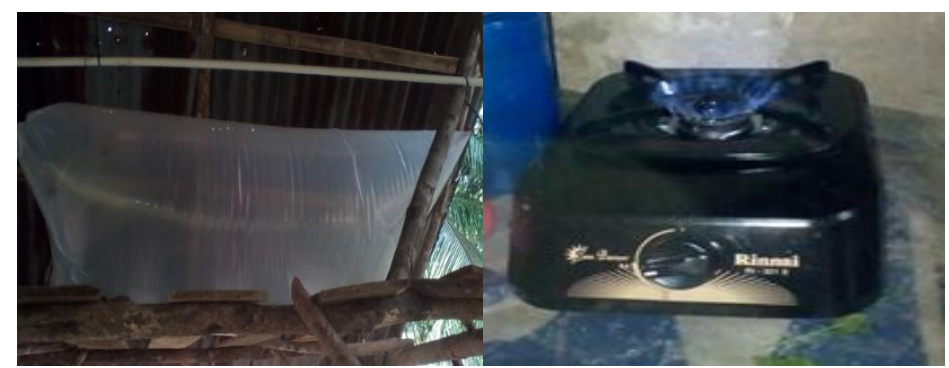

(a)

(b) 


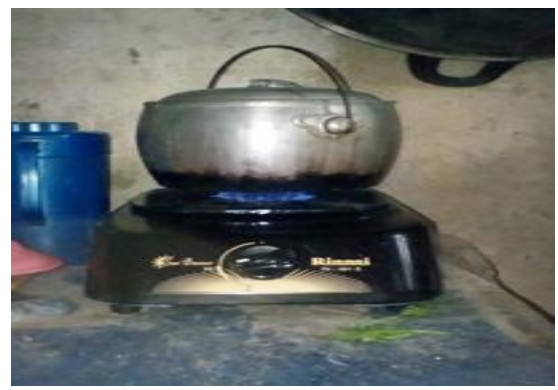

(c)

Gambar 8. Hasil instalasi biogas a) Penampung gas yang sudah terisi, b) bentuk gas yang dihasilkan, c) Gas digunakan untuk memasak

Hasil kegiatan pengabdian ini sangat besar manfaatnya bagi mitra. Selama ini kotoran sapi hanya menjadi limbah dan dibiarkan begitu saja. Setelah kegiatan pengabdian ini, mitra menjadi bisa mengolah kotoran sapi menjadi biogas. Mitra sangat berterima kasih terhadap kegiatan ini dan berharap berlanjut pada tahun-tahun berikutnya. Instalasi biogas ini menjadi contoh bagi anggota lain kelompok tani/ternak tersebut khususnya dan masyarakat Kelurahan Kandang Limun umumnya. Sehingga pada masa yang akan datang muncul instalasi biogas baru yang lebih banyak serta masyarakat tidak lagi tergantung pada gas dan akhirnya masalah kelangkaan gas dapat teratasi.

\section{KESIMPULAN}

Dari kegiatan ini dapat disimpulkan:

1. Pelatihan pembuatan dan pengoperasian instalasi biogas dengan sistem kontinu telah berhasil dilaksanakan dengan sukses.

2. Digester dengan kapasitas $2000 \mathrm{~L}$ dapat menghasilkan gas yang dapat dipakai sehari-hari dengan lama pemakaian \pm 1 jam.

3. Gas yang dihasilkan telah digunakan oleh mitra untuk memasak, seperti rebus air, menumis, dan menggoreng.

\section{UCAPAN TERIMA KASIH}

Terima kasih kepada Ditjen Dikti yang telah membiayai kegiatan pengabdian ini melalui skim Ipteks bagi Masyarakat (IbM) Tahun 2016. 


\section{DAFTAR PUSTAKA}

Andi, 2008, Teknik Pembuatan Instalasi Biogas Fakultas Peternakan Unpad. Bandung. http://peternakan.unpad.ac.id.

Ginting, E.H., 2006, Perancangan Fasilitas Biogas Kandang Terpencar Kelompok Ternak Tani Pandan Mulyo Dukuh Ngentak, Skripsi, Jurusan Teknik Fisika Fakultas Teknik, UGM, Yogyakarta.

Junus, M., 1987, Teknik Membuat dan Memanfaatkan Unit Gas Bio, Fakultas Peternakan Universitas Gadjah Mada, Gadjah Mada University Press, Yogyakarta. 